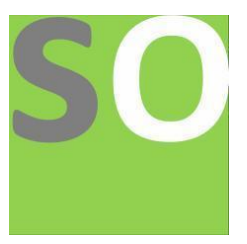

Article title: Medical Students Contribution as a Refining Tool for the Conventional Educational System Authors: Omar Atia[1]

Affiliations: Helwan University, Faculty of Medicine, Cairo, Egypt[1]

Orcid ids: 0000-0002-5371-0044[1]

Contact e-mail: omaratia49@hotmail.com

License information: This work has been published open access under Creative Commons Attribution License $\mathrm{http}: / / c r e a t i v e c o m m o n s . o r g / l i c e n s e s / b y / 4.0 /$, which permits unrestricted use, distribution, and reproduction in any medium, provided the original work is properly cited. Conditions, terms of use and publishing policy can be found at https://www.scienceopen.com/.

Preprint statement: This article is a preprint and has not been peer-reviewed, under consideration and submitted to ScienceOpen Preprints for open peer review.

Funder: None

DOI: 10.14293/S2199-1006.1.SOR-.PPRHDVR.v1

Preprint first posted online: 26 June 2020

Keywords: Autopsy, Case-Based Learning, CBL, Peer-to-Peer, Student contribution 


\section{Medical Students' Contribution as a Refining Tool for the Conventional Educational System}

\section{Abstract}

One of the most important things that accentuate an institution's greater advancement is its pursuit of change. Student contribution has been advocated for by many well-standing universities and has proven a better approach and a more refined way of an exuberant advancement both academically and personally. This article highlights how such contribution can be administered using novel approaches while preserving the main guidelines for graduating not only health care providers but also researchers and life-long learners. The new prospect of students as beneficial assets provides an educational institution with valuable creative ideas, eye sights that can detect points of possible reform in the educational system, and another significant voice to the making of future decisions. The faculty has successfully been able to apply certain characteristicsself-independence, new rational scope, practical and tutoring skills- to undergraduates through peer-to-peer learning technique, medical poster presentation skills, and case-based learning manner.

Key Words: Autopsy, Case-Based Learning, CBL, Peer-to-Peer, Student contribution

\section{Introduction}

Students' perspectives have always been an integral part of any institutional development. A "voice to be heard" pedestal is a hovering thought of their identity's existence and the buildup of their personal recognition, academic excellence, and the education's fore coming prestige.

Integration of the older-medical staff- and younger-medical students- generations' vantage points serves to be the hallmark of any advancement; the administrative "vision and mission" in harmony with a student's common individualistic goals, demands, and wants possess a better-paved route for the completion of their 
idealistic vision. The administrative hierarchy involving all the teaching staff must involve a student's viewpoint as a part of its decisions; the student serves to be a reflection of its actions and future achievements.

Set to enhance the teaching quality, provide another experiential scope for students and accept the mental change of recognizing the students' contribution as a pillar, the administrative plan included several activities to develop certain skills not only within students but also within the teaching staff; an integrative project that involves academic, social, and personal characteristics to be set as objectives.

\section{Case Studies}

\section{Q-Bank of CBL}

A good way to learn is to solve; a better way is to create those to be solved (Kelly et al., 2018).

A respected histopathologist advocates the students' enrollment in the academic knowledge and took the first steps to locate and motivate those gifted to include better approaches to structuring and solving case-based questions created by students for students. Such action has been taken after a thorough understanding of the college's needs and the students' wants in the form of a step-to-step approach to qualifying those to be involved.

1- Creating a well-formulated understanding of the importance of such an assessment tool and its well-fitted uses.

2- Creating a structured guide with all the rules to be implemented in the construction of a medically knowledge-based assessment with a common approach to the different processing of various medical students' mindsets.

3- Presenting the integral parts to being mount in a well-constructed case among creative medical scenarios.

4- Presenting an example of well-formulated cases with all the pillars and points of change to a group of prompting students.

5- Creating teams with different roles based on students' preferences and each individualistic insight of correctly recognizing points of strength and weaknesses 
6- Providing readily constructed case-based-questions based on every organ system to locate the points of weaknesses and various academic, and structural defects and correcting them.

7- Students are distributed into several groups; Case writers and Case Reviewers, with the latter to further assess the integrity and understanding of the new cases created by their fellow peers.

8- Cases reviewed are collected and sent to a higher academic staff member related to the subject's field for further assessment.

9- Approved cases are collected and stored while disapproved are sent for new construction with special emphasis to points of argumentative validity and correctness.

The result is an integration of the staff member's vision and experience with the students' enthusiastic approach to developing an academic assessment tool with their prints on it. The process has been fastidiously observed and documented by staff and administrative members. Personally, this pioneered approach to meeting students' contribution sets to be an exemplification of a faculty's quest for change and acquisition of a reputable image among others.

\section{Peer-to-peer PBL (Problem-Based-Learning)}

Despite minor differences in their perceptions, members of the same generation tend to have similar perceptive techniques to the spoken-out information. A peerto-peer technique for exchanging constructive advices and information sets to show outstanding developments in the medical academic levels of both members' sides (Mohammed et al., 2020). With the aim of a better informational exchange and students' contribution in both the accession of several teaching and communicating skills and benefiting other junior-level members in a less complicated manner, the administrative board has moved to put this idea into action. A PBL-Problem Based Learning- is the discussion of a medically constructed case scenario between several students and a tutoring staff member. The refinement of such a knowledge communicating tool by involving a senior medical student with an appropriate set of skills, training, and academic knowledge serves to stand out among the medical faculties in the region (Shankar and Nandy, 2016).

1- Several meetings with enthusiastic senior students are held to provide a better understanding of the aim and methods of the PBL. 
2- Several meetings are held to point out the step wise manner of locating golden clues within the case scenario and indirectly addressing them by the senior student.

3- Each senior student is required to put forth extensive research of the provided objectives.

4- Each senior student is required to present the researched objectives in front of fellow seniors and selected staff members.

5- Each senior student is then subjected to feedback critic from the staff members in the best constructive manner.

6- Each case scenario to be presented for junior students are firstly discussed by staff members and seniors before every scheduled session.

7- Senior students, now called peer tutors, are distributed among different groups with a certain number of junior students and a supervising staff member to further assess the tutoring, communicating, questions and obstacles handling skills in each session.

8- Peer tutors are provided with the feedback after every session to reform their shortcomings.

This new approach of "teach to learn" in the form of peer-to-peer learning is a superlative technique for faster academic enhancements and easier knowledgedelivery.

\section{Autopsy Tutoring}

Different medically constructive activities are performed in the summer with an open invitation to anyone eager to expand the scope of their knowledge and skills in a self-involved manner. A medically centered activity in the form of an autopsy carry-out sets to involve practical skills and theoretical knowledge of enthusiastic students. The histopathologist carries an organized plan with different tasks, creates surveys to collect positive responses from those willing, and implements training sessions for those applying to properly address certain crucial skills.

1- Several meeting sessions are held to readdress the importance of the abovementioned activity and to construct a better understanding of the activity itself.

2- Applied Students are provided with the needed academic materials and communicating guides to aid in their preparations.

3- Based on their past experiences, applied students are familiar with the step wise manner for better performance in the practical sessions.

4- Applied students attend two practical sessions: heart and brain autopsies.

5- Applied students perform in the presence of a supervising staff member. 
An unusual activity that focuses on gathering all theoretical knowledge and applying it practically with methodic steps and watchful experienced staff members.

\section{Poster/Research Presentation}

The role-playing of a mentor and his/her apprentices has been perfectly implemented in another activity; poster presentation. The faculty's histopathologist has been of great aid in the preparation and training of third-year students; the implementation of her past career experiences and resources as materials to be used for the creation of the poster shines a light on the critical contribution of the students in well-respected organized events and the recognition of those students in various competitions held by those organizations

among different medical schools. ECPT Annual Histopathology Conference-2020 serves as a starting point to the changing mindsets of accepting students as contributors to the high status of a faculty. A group of students has been chosen through a survey to compete in a poster/presentation under various medical headings; the topics were to be of the students' choices, and selected staff members were to be vacant for any assistance.

1- A survey with a meticulous selection based on motivational letters, past experiences in similar events, and various questions was created and sent by each student.

2- Students' responses were checked by the selected staff members and chosen based on a certain criterion.

3- Students formerly selected are reselected by the hosting organization's members.

4- Students reselected are distributed into two groups: poster presentation and power point presentation.

5- "Poster presentation" students are aided with meeting sessions to discuss their chosen topics and provided with proper tutoring.

6- "Poster presentation" students are provided with microscopic pictures by the histopathologist acting mentor.

7- "Power point presentation" students are aided with meeting sessions and mentors' perspectives regarding their plan, medical content, and presentation.

Such an event has come to be regarded as an emblem of students' contribution aided by different mindsets that are accepting change in the newly developed educational world and proving the importance of this contribution by the different achievements performed by students both personally and institutionally. 


\section{Conclusion}

It might seem visually distressing to disturb "steady waters", but with every innovative step, even if it seems Lilliputian, comes a challenging situation where all current systems and processes are questioned not for their efficacy rather for their validity. In the beginning, mental resistance to the contribution of students in every collegiate aspect existed, and such obstacle is both a challenge and an enigma, for it holds a new path to innovative academic strategies and lofty guaranteed academic excellence when endorsed.

\section{Take-home messages}

1- Understanding that a medical institution is not based solely on one stakeholder (educators) rather a group of differently representative stakeholders.

2- There must exist a conflation of disparate perspectives of the different existing stakeholders in the same institution for the sake of an esteemed status.

3- Students' skills can be upbrought by different techniques that are not exclusively dependent on prosaic academic assessment tools.

4- "Peer-to-peer" tool is a queer technique to guarantee a better way to teach with a closer approach to the common understanding between stakeholders of the same generation.

5- Q-bank serves to be an aberrant method to test the creativity of medical students and enrich the faculty's capacity with student-made resources.

6- Students taking part in prestigious events, especially those that expose them to real-life scenarios, allow their inner selves to develop with a more scholastic approach to their future medical careers. 


\section{Acknowledgments}

-The author honorably acknowledges Dr. Hebat Allah Ahmed Amin, MD pathology, Helwan University, Faculty of Medicine, Cairo, Egypt. FAIMER Fellow 2020.

-The author acknowledges "Medical Students Contribution to Curriculum Reformation and Faculty Development" project and its members for the outstanding performance and adept assistance.

\section{References}

- Kelly M, Ryan A, Henderson M, , et al. 2018, 'Students designing assessment for future practice', MedEdPublish, 7, [2], 53, https://doi.org/10.15694/mep.2018.0000121.1

- Mohammed Sami Hamad S, Iqbal S, Mohammed Alothri A, Abdullah Ali Alghamadi M, , et al. 2020, "'To teach is to learn twice" Added value of peer learning among medical students during COVID-19 Pandemic ', MedEdPublish, 9, [1], 127, https://doi.org/10.15694/mep.2020.000127.1

- Shankar P, Nandy A, 2016, 'Self-directed learning during problem-based learning sessions ', MedEdPublish, 5, [3], 3, https://doi.org/10.15694/mep.2016.000089 